\title{
«TRANSFORMAR LA SOCIEDAD. CAMBIAR LA VIDA». MUJERES ESPAÑOLAS ANTE EL MAYO FRANCÉS
}

\author{
«TRANSFORMING SOCIETY. CHANGING LIFE».
}

\section{THE ROLE OF SPANISH WOMEN IN THE FRENCH MAY}

\author{
Patricia Badenes Salazar \\ Instituto Universitario de Estudios Feministas y de Género «Purificación Escribano»
}

\section{RESUMEN}

El feminismo francés se reactivó, en parte, gracias al impulso dado por el Mayo del 68. Muchos de los rasgos del conocido como feminismo de segunda ola bebían de este acontecimiento. El Mayo alcanzó tal envergadura que dejó su impronta en España, un país fuertemente controlado por una dictadura, pero que comenzaba a despegar, en lo económico y en lo social sobre todo, y a acercarse a los países más avanzados de su entorno. Esta realidad iba de la mano de una creciente conflictividad social. Para los estudiantes más politizados, lo que estaba sucediendo en Francia se convirtió en un modelo a seguir en su lucha contra el régimen de Franco. La prensa española también se interesó por esta crisis. Las cada vez más numerosas periodistas españolas no dejaron de trasmitir los hechos más destacados y, por supuesto, dar sus opiniones, a veces muy progresistas. Por otro lado, las españolas que tuvieron la suerte de vivir el Mayo francés en primera persona no dudaron en participar y aprender de esta experiencia que las marcaría para siempre. El Mayo francés del 68 influyó en España y, cómo no, en las españolas que empezaban a tomar conciencia de que el mundo podía ser no sólo diferente, sino mucho mejor.

Palabras clave: Mayo francés del 68, España, mujer, feminismo, periodismo.

\section{ABSTRACT}

French feminism was reactivated, partly, due to the impulse of May 1968. Many of the traits of the Second Feminist Wave nourished from this event. May reached such a scale that left its mark in Spain, a country strictly controlled by a dictatorship, although it had begun to reemerge, economically and socially above all, and to resemble to the most advances countries in its context. This reality went hand in hand with a growing social conflict. For the most politicized students, what was happening in France became a role model in their struggle against Franco's regime. The Spanish press was also interested in this crisis. The increasingly number of Spanish journalists did not stop transmitting the most outstanding facts and, of course, giving their, sometimes, very progressive opinions. On the other hand, Spanish 
women who were lucky enough to live the French May in first person did not hesitate to participate and learn from this experience that would mark them forever. May 1968 influenced Spain and, of course, Spanish women who started to realize that the world could be not only different, but much better.

Keywords: May 68, Spain, woman, feminism, journalism.

\section{SUMARIO}

1.- Introducción. 2.- El Mayo francés del 68 y el movimiento feminista. 3.- La acogida del Mayo francés entre las autoridades franquistas y la «oposición». La visión de Dolores Ibarruri. 4.- Las periodistas españolas hablan del Mayo francés del 68. 5.- Españolas en el París del 68. 6.- Las obreras españolas en Francia. 7.- Bibliografía. 8.- Hemerografía

\section{Introducción}

El 2018 que ahora termina será recordado, entre otras muchas cosas, como el año del gran aniversario del Mayo francés del 68. Cincuenta años después de este acontecimiento trascendental en la historia de Occidente podemos decir, sin temor a equivocarnos, que se ha producido su última gran revisión, al menos en la que sus protagonistas estaban todavía en activo. Éstos le han dedicado sus últimas reflexiones, sus últimos recuerdos, sus últimas nostalgias... Ha sido su postrera ocasión de consagrarle unas palabras finales, de amor o de odio, depende de cada cual. Sus voces ya no estarán en la próxima gran efeméride. Esperemos que a los jóvenes de ahora todavía les siga interesando para que no se apague la llama del Evento definitivamente. Nuestra tarea es inculcarles esa pasión y recordarles que no sabemos cómo sería el mundo actual si el Mayo no hubiera tenido lugar, pero que intuimos que hubiera sido sin duda un mundo peor.

¿Qué nos lleva a hacer tal afirmación? El Mayo francés del 68 fue el despertar de muchos aspectos positivos que todavía hoy disfrutamos. Sin ir más lejos, le debemos la revitalización del movimiento feminista de los años setenta, la denominada segunda ola'. Para muchos expertos, los acontecimientos del 68, en general, representaron una especie de acelerador de una serie de dinámicas de cambio latentes, que iban a perdurar en el tiempo, entre ellas, el nuevo papel de la mujer en la sociedad. Pero antes de llegar a este punto, revisemos su relación con la Primavera francesa, para luego sumergirnos en la influencia de ésta en la España de la época desde una perspectiva de género. 


\section{El Mayo francés del 68 y el movimiento feminista}

En este punto, vamos a partir de una evidencia: no se puede comprender la reactivación del feminismo francés de los años setenta sin ponerla en relación con el Mayo del 68. Son muchos los que opinan que la verdadera causa del inicio del movimiento estudiantil fue la pervivencia de la prohibición de hacer visitas a las residencias del sexo contrario. En parte, tienen razón. Pero no debemos olvidar que existieron muchos más motivos. Por ejemplo, el recrudecimiento de la guerra en Vietnam; conflicto que era vivido por los jóvenes franceses más politizados como suyo propio y en el que volcaban toda su energía, defendiendo a su maltrecha población.

El rigor moral que se imponía a la juventud era un aspecto más de una sociedad arcaica y represora que no les satisfacía. En este sentido, cabe entender el éxito que por aquellos días alcanzaron las ideas rompedoras de la Internacional Situacionista.

Efectivamente, estos artistas vanguardistas, que acabaron constituyendo un grupo revolucionario que se anticipó a Mayo, participó en él y extrajo sus consecuencias cuando todo terminó, dedicaron una buena parte de sus escritos a desentrañar el porqué del malestar juvenil, tanto en Francia como en el resto del mundo. Así por ejemplo, en el conocido panfleto De la misère en milieu étudiant considérée sous ses aspects économique, politique, psychologique, sexuel et notamment intellectuel et de quelques moyens pour y remédier ${ }^{2}$, el tunecino Mustapha Khayati llevaba a cabo un exhaustivo análisis de las múltiples facetas en las que la vida de un joven podía verse afectada. Por supuesto, su situación sexual era abordada, aunque muy someramente. En un contexto que este autor describía como de miseria total, la juventud francesa imitaba las actitudes amorosas y eróticas de sus mayores. Conscientes de la importancia del amor y de su capacidad para hacer de la vida algo apasionante, los situacionistas abordaron el tema, pero no lo convirtieron en un pilar fundamental de su arquitectura teórica y en sus aproximaciones a este asunto la ambigüedad era la tónica dominante.

Relacionado también con este tema, el 8 de enero del 68, tuvo lugar un accidentado episodio que daría popularidad al todavía desconocido Daniel Cohn-Bendit. François Misso$\mathrm{ffe}$, ministro de Juventud y Deportes, fue a Nanterre a inaugurar una piscina. En un ambiente tenso, Cohn-Bendit le preguntó por qué no aludía en su último informe sobre la juventud a los problemas sexuales de ésta. El ministro no se lo pensó dos veces y le dijo que si tenía esa clase de conflictos se remojara en la piscina. El joven le afeó su respuesta conservadora y represiva.

2 Sobre la miseria en el medio estudiantil considerada en sus aspectos económico, político, psicológico, sexual y especialmente intelectual y sobre los medios para remediarlo. Consultar en: VIÉNET, René et al. (1998). Enragés et situationnistes dans le mouvement des occupations, París: Éditions Gallimard, pp. $219-243$. 
De este ministro y del Gobierno del que formaba parte no cabía esperar un gran apoyo a este tipo de asuntos, al igual que al de la lucha por la mejora de la situación de las mujeres. En cambio, sí que se presumía una mayor comprensión por parte de los partidos y de los sindicatos de izquierda. Esa era la teoría, la realidad era otra muy diferente...

El Partido Comunista Francés (PCF) y los principales sindicatos obreros -CGT y $\mathrm{CFDT}^{3}$ - defendían el carácter emancipador del trabajo femenino, pero se mostraban bastante reacios a permitir la libertad de contracepción y el aborto, al menos su cúpula directiva. El control de la natalidad era percibido por éstos como un dardo envenenado que lanzaba la burguesía capitalista para debilitar a la clase obrera. La Union des Femmes Françaises (UFF) (Unión de Mujeres Francesas) -organización dependiente del PCF- también tenía otras preocupaciones más «importantes», como lograr la paz en el mundo de la mano de la URSS. Luego abordaremos el testimonio de dos españolas que participaron en uno de los congresos de esta organización.

El impulso dado por El segundo sexo de Simone de Beauvoir se quedó bloqueado durante décadas por esta visión rancia de la izquierda francesa, que veía el feminismo como una forma de desunión. El Mayo francés del 68 y el movimiento feminista que nació, sino de sus entrañas, al menos de su ímpetu, serían la ocasión de revisar esta injustificable interpretación de la lucha por la igualdad de las mujeres más allá del plano laboral.

En un capítulo del libro 1968. El mundo pudo cambiar de base, Josette Trat analiza, entre otros aspectos, la relación del Mayo francés y del movimiento feminista de segunda ola. Para esta autora, lo que sí queda claro es la intensa participación de las mujeres en todas las facetas de este movimiento estudiantil y obrero:

La ausencia de una expresión feminista significativa durante Mayo del 68 puede parecer paradójica, ya que las estudiantes se movilizaron en los anfiteatros y las manifestaciones tanto como sus camaradas masculinos. Fueron muchas también las que animaron los comités de acción, en la Universidad y en los institutos, o en los barrios de numerosas ciudades. Fueron huelguistas en las empresas. Tantas veces consideradas simples auxiliares, habrían tenido mucho que decir sobre su lugar en este movimiento y sobre la interpretación machista de la «liberación sexual». ¿PPor qué entonces no tomaron la palabra para hacer oír su voz? (2008: 126)

Son varias las razones que aduce Trat: la liberación que supuso para estas jóvenes poder participar, codo con codo, con sus colegas masculinos, tras largos años de segregación; la prioridad concedida al triunfo de la Revolución por encima de cualquier otra Travail (Confederación Francesa Democrática del Trabajo). 
demanda; el carácter excesivamente violento de algunas de las acciones de protesta de los chicos jóvenes que alcanzaban un cierto protagonismo; la organización poco democrática y casi espontánea del movimiento en general, que, de haber sido más participativo, hubiera aupado a ciertas mujeres a la cabeza de éste, etcétera. Estemos o no de acuerdo con todas estas justificaciones, lo cierto es que el movimiento feminista francés de los primeros setenta heredó del Mayo muchas de sus formas de acción, si bien no fue su única influencia. Con su «progenitor» tenía en común: la juventud y la vinculación de sus componentes con la Universidad, parte de sus influencias intelectuales -las mujeres añadían las lecturas de las feministas americanas-, su radicalidad, su antiautoritarismo, su antiparlamentarismo, su distancia con respecto a los valores de la derecha y de la izquierda tradicionales, su gusto por las acciones con pocas participantes y cargadas de humor y por las asambleas generales...

Resumiendo, cuando analizamos el Mayo francés desde una perspectiva de género, lo primero que constatamos es que ningún nombre de mujer ha pasado a la Historia ni como protagonista de la revuelta estudiantil ni del posterior movimiento huelguístico. Asimismo, destaca una sorprendente falta de reivindicaciones encaminadas a mejorar la situación de la mujer, sobre todo en el terreno laboral. Dicho lo cual, no se puede afirmar que las mujeres no participaran y no se implicaran en todas las acciones de protesta llevadas a cabo esos días de humo y furia. Algún testimonio viene a contradecir esta supuesta falta de iniciativa. La activista Anne Zelinski, con la ayuda de una amiga, se propuso cubrir las paredes de la Sorbona con frases ingeniosas de autores famosos, como Charles Fourier, dedicadas a las mujeres. Con la misma pasión e intencionalidad, también realizaron una serie de charlas sobre temática femenina, como «mujeres y revolución». Así nos lo cuenta ella:

Entonces cuando llegó Mayo, yo estaba allí con mi amiga, deambulábamos por la Sorbona todo el tiempo, respirábamos ese aire, nos llenábamos de esa atmósfera. Hacía ya 15 días que la revolución estaba «hecha» y... nada sobre «mujeres» en todo esto. Entonces, con mi compañera, $[\ldots]$, estábamos sentadas en los escalones de la Sorbona y nos dijimos: «Todo esto es genial, pero no se habla nada sobre las mujeres. $\dot{\partial}^{Y}$ si hacemos alguna cosa por las mujeres?». Dicho y hecho. De entrada, empezamos a coger papel y pegarlo sobre los muros con frases de autores conocidos, como Fourier, sobre las mujeres. Después subimos a la sala de reservas y le dijimos al peludo que estaba de servicio: "Oye, ¿̇no hay debate sobre las mujeres?». Él nos respondió: «Pero es genial! Organizad un debate. ¿Qué queréis como título?». «iLas mujeres y la revolución! ¿̇Por qué no?», «De acuerdo, bien, ¿qué día os marco?». Reservamos el anfiteatro Descartes y organizamos el «primer» debate sobre las mujeres y la revolución (Linhart, 1989: 129-130). 
Zelinski, a continuación, describe el debate y reconoce que fue un éxito. Luego vinieron otros más, con conferenciantes de prestigio -Gisèle Halimi y Évelyne Sullerot-, pero ya no fueron ni tan espontáneos ni tan dinámicos. Esta incansable activista admite que ninguna de las acciones y que ninguno de los logros del movimiento feminista de los setenta hubieran sido posibles sin el concurso del Mayo del 68. A ella Mayo le enseñó que luchar por los demás era también luchar por ella misma.

Tras el final de la crisis y con el regreso al orden institucional, llegó la hora de la verdad. Algunas concesiones se imponían al «nuevo» Gobierno de Charles de Gaulle si no se quería volver a las andadas. Así por ejemplo, a las mujeres se les otorgó algo tan evidente como el derecho a poder abrir una cuenta bancaria sin necesitar el permiso del marido y la autoridad conjunta sobre sus vástagos. Pero, a nuestro entender, los cambios más trascendentales tuvieron lugar más tarde, ya iniciados los setenta, cuando un grupo importante de mujeres puso en marcha su propio movimiento reivindicativo, influidas por las ideas combativas de Mayo.

En efecto, el 26 de agosto de 1970 tuvo lugar el que ha sido considerado el acto inaugural del Mouvement de libération des femmes (Movimiento de liberación de las mujeres). Bajo el parisino Arco de Triunfo, nueve mujeres militantes dejaron un ramo de flores en honor a la Mujer del soldado desconocido. En las pancartas que llevaban podían leerse lemas tan sesentayochistas como: «ll y a encore plus inconnu que le soldat inconnu, c'est sa femme» (Todavía existe alguien más desconcido que el soldado desconocido, su mujer) y «Un homme sur deux est une femme» (Un hombre de cada dos es una mujer). Se trataba de un gesto simbólico que enlazaba con otro similar realizado en Mayo del 68, dos años antes, por un grupo de jóvenes rebeldes que provocó un gran malestar entre los miembros del Gobierno y entre la ciudadanía.

Éstas no fueron las únicas herencias sesentayochistas en el movimiento feminista francés. Enumeremos algunas de ellas, completando las argüidas por Josette Trat: en primer lugar, el recurso a los gestos provocativos y a las acciones rápidas; en segundo lugar, el caldo de cultivo que representaron las reuniones pos 68 para analizar y debatir sobre cuál había sido el papel de las mujeres en el movimiento contestatario; en tercer lugar, la formación ideológica que recibieron muchas de estas mujeres en el seno de los grupos de extrema izquierda, protagonistas del Mayo; en cuarto lugar, la liberación de las costumbres, que triunfó entonces, facilitó la consolidación de la idea de la libre disposición del cuerpo, tanto para evitar los abusos sexuales como para encumbrar el propio disfrute sexual y la libre elección de la maternidad; por último, la convicción de que lo personal era político. Las mujeres españolas todavía tendrían que luchar más tiempo... 


\section{La acogida del Mayo francés entre las autoridades franquistas y la "opo- sición". La visión de Dolores Ibarruri}

Los cambios económicos y, en consecuencia, los cambios sociales que se produjeron en la década de los sesenta iban a repercutir, indefectiblemente, en la situación de la mujer española. Ya a mediados de los cincuenta, la gravísima crisis que atravesaba la economía española forzó a las autoridades a cambiar de rumbo, es decir, a abandonar la autarquía y a mirar hacia el exterior. En los sesenta, España inició una tímida andadura hacia el capitalismo, tanto tiempo denostado por la dictadura. Este hecho ocasionó, a su vez, un conjunto de mutaciones sociales que conllevarían nuevos hábitos y una nueva mentalidad entre los españoles y las españolas, para disgusto de los dirigentes franquistas.

Desde el punto de vista del nacionalcatolicismo, la familia era una institución básica y, en ella, la mujer sólo debía ejercer de buena esposa y de buena madre, a ser posible de una vasta prole. El sistema jurídico, por su parte, se encargaba de sancionar esta situación de sometimiento y abnegación. Afortunadamente, los aires de cambio también llegarían hasta esta rancia forma de concebir la familia, sobre todo entre las mujeres más jóvenes y formadas, quienes fueron concienciándose de que el modelo patriarcal era simplemente una opción y no una necesidad. En este sentido, el incremento de los contactos con sus vecinas europeas iba a jugar un papel clave. Pero, evidentemente, no fue el único factor de cambio: la pérdida de peso de instituciones como la Iglesia y la Sección Femenina, el acceso generalizado a la educación -en 1968, el $40 \%$ de los alumnos de bachillerato y el $30 \%$ de los universitarios, aproximadamente, eran mujeres-, el incremento de su presencia en el mundo laboral, la incorporación de nuevos métodos anticonceptivos, etcétera. Esta nueva mujer recortará distancias con las de su entorno y, cómo no, con las francesas.

En este contexto, al que se añadía un considerable repunte de la conflictividad estudiantil y obrera, el Gobierno español se vio obligado a posicionarse y a actuar ante la revuelta que se estaba produciendo en el país vecino. Francisco Franco, que, en el fondo, sentía una cierta admiración por el presidente De Gaulle, no dudó en recriminarle su tibieza a la hora de plantar cara a la crisis y su «peligrosa» apuesta por el «nefasto» pluralismo político. Para el dictador, la solución consistía en erradicar, sin titubeos, el caos social y político, lides en las que él tenía gran experiencia. Por su parte, Luis Carrero Blanco, a la sazón vicepresidente del Gobierno, lo sintió como un lujo que aquella España, que comenzaba a despegar en lo económico, no podía permitirse. El ministro de Información y Turismo, Manuel Fraga Iribarne, aparte de tener informados a estos dos dirigentes de la última hora francesa y de tratar de explicarles los entresijos del conflicto, debía ocuparse de la llegada 
de la información procedente del otro lado de la frontera de los Pirineos. Para evitar posibles emulaciones, Fraga intentó establecer una especie de cordón sanitario en torno a la prensa española. A pesar de la dificultad de este empeño, encontramos algunos ejemplos, como todo lo acaecido al diario Madrid, cuya edición del 30 de mayo fue secuestrada. Posteriormente, el vespertino madrileño recibió una dura sanción, que representó un largo período de cierre y una cuantiosa multa.

Desde la «oposición», Santiago Carrillo, uno de sus principales líderes, que, además, se encontraba en Francia cuando estallaron las primeras revueltas, realizó una interpretación de estos hechos totalmente contraria a la de los gerifaltes de la dictadura. Según el dirigente comunista, la gran huelga general que siguió a los primeros altercados estudiantiles proporcionaba un magnífico modelo a seguir en España. La anhelada «gran huelga nacional» podía devenir en un excelente mecanismo para acabar con la dictadura de Franco. Esta clara defensa del Mayo francés, como ejemplo indiscutible de un posible triunfo de la revolución socialista en un país capitalista y desarrollado, le alejó irremisiblemente del Partido Comunista Francés, cuyos cabecillas no apoyaron a los estudiantes desde un primer momento y cuando lo hicieron no supieron hacerlo con tacto.

Dolores Ibarruri, su compañera de partido, dio una conferencia que llevaba por título "Vivencia y actualidad del marxismo», con motivo del 150 aniversario del nacimiento de Karl Marx, en el Instituto del Movimiento Obrero Internacional el 30 de mayo del 68. El texto que expuso hacía referencia, inevitablemente, a los sucesos que acaban de tener lugar en Francia:

Las impresionantes luchas que se desarrollan en Francia, -en la Francia de la Gran revolución burguesa y de la Comuna; en la Francia, que los cantores del capitalismo presentaban como uno de los países de la opulencia y del bienestar-, luchas que sacuden hasta los cimientos de la sociedad francesa, han hecho añicos las teorías seudocientíficas y antimarxistas de la conciliación y del aburguesamiento de la clase obrera.

Estas luchas han puesto al descubierto el inmenso abismo que existe entre la burguesía monopolista y los trabajadores; han sacado a la luz el descontento, las brutales carencias y la profunda insatisfacción de millones de obreros, de técnicos, de ingenieros, que tras una fachada de lujo y de aparente prosperidad, viven difícilmente, en esa llamada sociedad de la opulencia (Nuestra Bandera, tercer trimestre de 1968, p. 65).

Al movimiento huelguístico y de protesta francés todavía le quedaban unas largas semanas de lucha cuando Ibarruri escribió este documento. Por este motivo, aún había lugar a la esperanza, como se aprecia en estas líneas reproducidas. La gigantesca huelga mantenida por los obreros de este país -ejemplo de bienestar y prosperidad- ha puesto de 
manifiesto que la situación no era tan idílica como parecía, ni los trabajadores estaban tan adormecidos, ni nadaban en la abundancia. Para la lideresa comunista, en España también se están desarrollando importantes luchas, dirigidas por las Comisiones Obreras y contra una sanguinaria dictadura, pero con el mismo fin que en Francia: ampliar los márgenes de la democracia -en nuestro caso, mucho más- e instaurar la sociedad socialista.

\section{Las periodistas españolas hablan del Mayo francés del 68}

La prensa española del último tramo de la década de los sesenta estuvo inevitablemente marcada por la Ley de Prensa e Imprenta de 1966. Una ley puesta en marcha por Manuel Fraga, no con pocas reticencias por parte de los sectores más conservadores del franquismo, con el objetivo de hacer un periodismo más veraz y menos monolítico. A pesar de todas las prudencias con las que se elaboró y de todas las matizaciones posteriores, lo cierto que esta norma representó un soplo de aire fresco en el anquilosado panorama periodístico español. El fin de la censura previa y una mayor predisposición a abordar temas antes considerados tabús facilitaron el desembarco de las noticias, muy agitadas, que llegaban de la vecina Francia. Los principales diarios y revistas españoles del período siguieron con gran interés el desarrollo de la crisis social y política francesa, a través de crónicas, de artículos de opinión, de reportajes e incluso de series.

De todas las crónicas que se escribieron durante la crisis francesa, por parte de corresponsales españoles en ese país, destacaremos las de la periodista Pilar Narvión ${ }^{5}$. Una de las pocas mujeres que, bastantes años después, llegó a ocupar un puesto relevante en un diario de gran trascendencia: Pueblo.

Este órgano del Sindicato Vertical era uno de los vespertinos madrileños de mayor tirada en el 68, con lo cual los artículos de Narvión sobre el Mayo francés eran muy leídos. Al igual que el resto de corresponsales extranjeros en París, la periodista de Pueblo se disponía a cubrir las anodinas y tal vez improductivas Conversaciones para la Paz en Vietnam, que estaban previstas para el mes de mayo de 1968. Pero, como todos sabemos, hubo una serie de acontecimientos inesperados que hicieron que sus miradas se dirigieran hacia un foco mucho más interesante.

Ya en la portada de la edición del día 4 de mayo de este periódico aparecieron las primeras algaradas estudiantiles, que no abandonarán esta posición privilegiada en todo el tiempo que dure el conflicto. En sus crónicas, Pilar Narvión no se limitaba a informar sobre los 
sucesos más destacados, le gustaba indagar en las causas que los motivaban y en proponer posibles soluciones, como reformar la Universidad. En numerosas ocasiones, denunciaba la brutalidad policial y se ponía de parte de los estudiantes, de quienes alababa su habilidad táctica como "guerrilla urbana» y su capacidad de organización. Así se refiere la corresponsal a una de estas acciones policiales: "Las cargas de la Policía fueron terriblemente brutales y uno de mis colegas, viejo reportero que es un archivo vivo del París contemporáneo, nos aseguraba que jamás desde el final de la guerra se habían visto manifestaciones de una violencia tan dura en la ciudad» (Pueblo, 7 de mayo de 1968, p. 13).

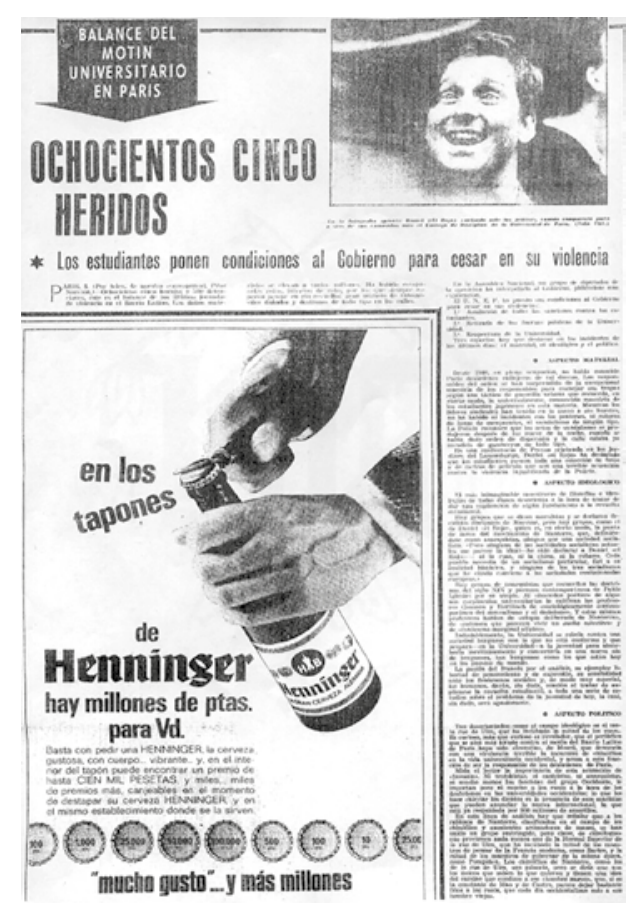

[Fig. 1]. Pueblo, 8 de mayo de 1968, p. 8.

Como curiosidad, en su crónica del día 8 de mayo, aparece la famosa imagen del líder estudiantil Daniel Cohn-Bendit sonriendo burlonamente a un CRS 6 , publicada antes en la 
revista Paris-Match y convertida en uno de los iconos de la revuelta estudiantil [Fig. 1]. Tanto éxito tuvo que el artista Bernard Rancillac la transformó en uno de los centenares de carteles que invadían los muros de toda Francia, con el texto, primero, de Nous sommes tous des Juifs et des Allemands, y más tarde convertido en Nous sommes tous «indésirables») [Fig. 2 y 3 ].
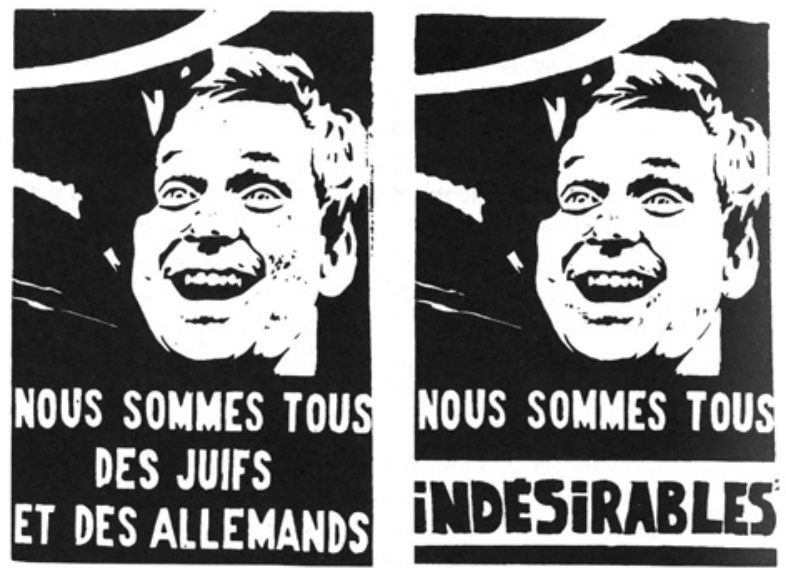

[Fig. 2]. Nous sommes tous des Juifs et des Allemands, azul oscuro sobre fondo blanco, $65 \times 40 \mathrm{~cm}$, papel de periódico, serigrafía.

[Fig. 3]. Nous sommes tous des Indésirables, negro y rojo sobre fondo blanco, $55 \times 43 \mathrm{~cm}$, papel offset, offset.

En la edición del día siguiente, el jueves 9 de mayo, descubrimos dos crónicas de Pilar Narvión; una sobre las revueltas estudiantiles de París y otra sobre las Conversaciones para la Paz en Vietnam. La periodista aragonesa encuentra entre la prensa francesa del momento una caricatura que fusiona muy bien estos dos temas de tanta actualidad y que ella nos describe: «Una caricatura publicada por Paris-Press ayer representa al general De Gaulle recibiendo en su casa a la paz con estas palabras: «Señora, espero que le gusten los niños». Tras del general se adivina todo el mobiliario de la casa destrozado por esos «enfants terribles» de la ciudad que han sido en los últimos días los estudiantes» (Pueblo, 9 de mayo de 1968 , p. 12). El recurso a los datos ofrecidos por la propia prensa gala o por colegas franceses bien informados será muy habitual tanto en Narvión como en los otros corresponsales españoles, como podemos comprobar en la primera cita transcrita.

El estilo periodístico de Narvión adquiere, frecuentemente, toques literarios y recurre a lo anecdótico para construir su relato. Así, en su crónica del día 13 de mayo, podemos leer: 
Junto a mí, un orondo caballero decía a su mujer, con acento extremadamente irritado, viendo a las brigadas de argelinos y portugueses poner en su sitio los adoquines:

-Cuando los señoritos superdesarrollados hacen motines filosóficos los viernes, los desgraciados obreros subdesarrollados tienen que trabajar de sol a sol el domingo.

La que parecía hija del matrimonio, una chiquilla de no más de quince años, le respondió como una flecha:

-Si no hubiese motines como los del viernes, no habría esperanza para ningún desarrollado ningún domingo (Pueblo, 13 de mayo de 1968, p. 8).

Estos «motines filosóficos» han llamado más la atención de los dos mil periodistas congregados en París que las monótonas conversaciones para la paz. Para Narvión, este hecho explica la repercusión mediática mundial de la crisis estudiantil francesa; a la que defendió más en su momento que muchos años después, cuando tuvimos la suerte de entrevistarla. Creemos que con el tiempo perdió la perspectiva de la trascendencia del evento histórico que tuvo la fortuna de vivir en primera persona. Otra periodista que habló de Mayo -más bien, del espíritu rebelde de la época- fue Elisa Lamas, en esta ocasión para la revista catalana Destino.

En «La mujer de su casa y la rebeldía de la juventud», aparecido en el número del 1 de junio, la autora, que se define como «mujer de su casa»-expresión afortunadamente poco utilizada hoy-, reflexiona sobre el papel de las mujeres en la revuelta y acaba reconociendo su débil influencia en la sociedad por falta de poder político. Aunque, por otro lado, considera que son precisamente las madres quienes transmiten los valores a sus hijos e hijas:

Nuestra responsabilidad es enorme, por desgracia. Somos nosotras en gran medida las encargadas de proporcionar ideales a nuestros hijos. Si el hogar tiene un papel fundamental, ése es: transmitir pautas de vida; $y$, ¿̇qué ideales presentamos a nuestros hijos? Me refiero, claro está, no a lo que les decimos, sino a las metas que de verdad buscamos en nuestra manera de vivir. No es fácil engañar con palabras a los niños ni a los jóvenes; ellos tienen un instinto finísimo para distinguir lo verdadero de lo falso (Destino, 1 de junio de 1968, p. 29).

En general, se trata de valores positivos, como la generosidad y el altruismo, que los adultos no sólo deberían consentir, sino favorecer. Otro tema que Lamas aborda de soslayo y que retrata muy bien uno de los ideales de la época y que, a su vez, viene de muy antiguo es el de la sociedad del futuro en la que las máquinas harán todo el trabajo duro y las personas podrán dedicarse a cultivar sus talentos y a explorar su creatividad, si bien la autora está pensando más en tener tiempo para consagrarse a las «causas altruistas»:

Los jóvenes desean una sociedad donde, gracias al esfuerzo de todos, el bienestar mínimo 64 esté asegurado, y quede así libre un potencial inmenso de energía, entusiasmo y tiempo para 
trabajar, cada uno según su personal vocación, por causas altruistas. Esto es en el fondo lo que piden los estudiantes que aclaman a Fidel Castro o a "Che» Guevara. Y no es una utopía, un ideal irrealizable. El progreso de la ciencia en todos los órdenes, las nuevas técnicas, los avances de las disciplinas sociales y políticas permiten esa moderna sociedad (Destino, 1 de junio de 1968, p. 29).

\section{Españolas en el París del 68}

Elisa Lamas vivió las revueltas de lejos, pero, sin duda, hubo otras muchas españolas que, como Pilar Narvión, lo experimentaron en sus propias carnes. Gracias a un reportaje del inclasificable Manuel de Agustín, entonces corresponsal en París del diario Arriba, tenemos constancia de la presencia de mujeres durante la ocupación del Colegio de España, la mayoría seguro que eran españolas. Recordemos que el 21 de mayo de 1968, al calor del movimiento de las ocupaciones de espacios públicos o privados, un grupo de estudiantes y de trabajadores españoles procedieron a tomar esta ilustre institución, sita en la Ciudad Internacional universitaria.

Así lo refiere De Agustín en su crónica de la edición del día 24: «Las camaradas, que son unas muchachas casi tan sucias como los chicos y con aspecto de tan poco estudiantes como el resto de la multitud que allí hemos visto, van de un lado para otro con el pitillo en la mano izquierda y un cacharro en la derecha» (Arriba, 24 de mayo de 1968, p. 12.). En apenas tres líneas, con un tono de lo más ofensivo, deja a las chicas que participan en la ocupación por los suelos. Las tacha de sucias y de vagas y reduce su colaboración a tareas de cocina.

El título del artículo ya es toda una declaración de intenciones: «La cochambre roja ha invadido el pabellón español de la Ciudad Universitaria de París», precedido del subtítulo: «Un bochornoso espectáculo». Los chicos no salen mejor parados que sus compañeras: «En el recibidor nos encontramos a cinco o seis caballeretes deambulando. No tienen aspecto de estudiantes. Parecen más bien obreros; pero tampoco obreros de los que trabajan, sino de los que no hacen nada; de aquellos que no tienen tiempo de lavarse, ni de afeitarse, ni de peinarse, ni siquiera de llevar los dientes aseados» (Arriba, 24 de mayo de 1968, p. 12). Sobran los comentarios.

En el lado opuesto, hallamos los comentarios que, el recientemente fallecido, Ramón Luis Chao les dedica en El Alcázar. Este corresponsal, que nos comentó ufano en una entrevista que era amigo personal de los líderes estudiantiles franceses y que había vivido en el Colegio de España durante cuatro años, describe con emoción este mismo acontecimiento y reconoce las dificultades que tiene para hacer su trabajo de periodista en un lugar que siente 
como su casa. Asimismo, admite lo fácil que es dejarse seducir por el ambiente: «Es difícil realizar un reportaje objetivo, dado el clima apasionado que reina» (El Alcázar, 22 de mayo de 1968 , p. 3). Para Chao, esta vetusta y prestigiosa institución se había convertido en una especie de «pequeña Sorbona», en la que la Palabra deambulaba suelta, sin ataduras.

Con el pretexto de esta ocupación, el Gobierno franquista cerró las puertas de una entidad que se había vuelto demasiado «incómoda» y con cuyos valores no congeniaba. Hasta el curso 1987-1988, ya bien instalada la democracia, sus vanos no serían reabiertos.

Estos jóvenes españoles y, a veces, no tan jóvenes, ya fueran estudiantes o trabajadores, no fueron los únicos que participaron en el movimiento estudiantil francés, primero, y obrero, después. En efecto, el Mayo del 68 marcó de forma directa a los estudiantes y a los trabajadores españoles de ambos sexos que estaban en Francia o en el propio París; quienes no dudaron en participar en las manifestaciones y demás acciones de protesta y, por supuesto, en las ocupaciones, tanto de centros educativos y culturales como de fábricas, con todo lo que ello conllevaba [Fig. 4]. De entre ellos, iba a destacar una todavía desconocida Emma Cohen. Recorramos de su mano y con su palpitante diario el París de la Comuna.

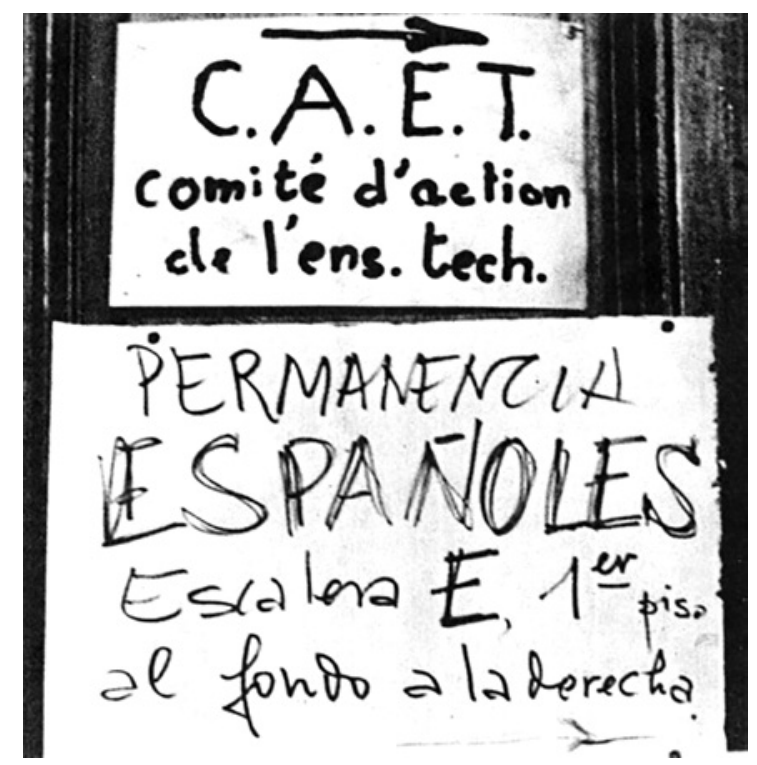

[Fig. 4]. Cartel de los estudiantes españoles en la Sorbona ocupada. En Índice, número doble 233-234, julio-agosto 1968, p. 10. 
Emma Cohen tuvo la suerte de estar en el lugar adecuado en el momento adecuado. Llegó a París por casualidad. El temor a la monotonía y a la opresión que le aguardaban en España la animaron a prolongar su estancia en el país vecino. Para su sorpresa, iba a vivir uno de los momentos más intensos de su existencia y tuvo el acierto de anotar sus vivencias y de describir sus sentimientos en un detallado diario, al que llamó La libreta francesa ${ }^{7}$. Emma aprovechó muy bien su estancia en París y visitó los sitios más representativos. Por ejemplo, en el teatro del Odeón, participó en varias comisiones. No le tembló el pulso a la hora de ayudar a preparar cócteles molotov y colaboró en la recogida, en la selección y en la difusión de información sobre los eventos que sacudían el país. Pero, más acorde con sus gustos, se apuntó a la comisión «Théâtre dans la Rue» («Teatro en la calle»). Así nos narra lo fundamental de su experiencia:

21 de mayo, martes.- Los del «Théâtre dans la Rue» formamos en el Odeón cuatro equipos de doce que parten hacia puntos opuestos de la ciudad. En place du Trocadéro, alrededor de un amplio círculo de tiza, a modo de señuelo, lanzamos preguntas actuales. Se nos pela la garganta mientras los curiosos se acercan. Al principio nuestras preguntas van al aire: los pocos que leen sobre el asfalto, dentro del círculo, «ici, on joue au jeu des questions» ${ }^{8}$, se quedan nota. Detrás de mí alguien susurra «tontería mayúscula». A punto yo de ceder al desaliento, uno contesta a algo sobre De Gaulle, del otro lado, la ciudadana que ya le rebate, para tener más cerca al hombre, pisa sin querer el círculo, entra, contesta un tercero, otro más..., se forma una burbuja parlante, permanezco en ella por si decrece la parlanchina prima y el resto provoca sucesivos focos parejos. Hasta armarla. Bulle vida. Tras dos horas de intenso esfuerzo bulle vida ansiosa de más entendimiento en Trocadéro. Dejamos la plaza con tropecientos viandantes discutiendo. "Théâtre dans la Rue» logró este Trocadéro, este nuevo y fugaz paraíso de discusión autónoma. Siquiera por un instante paladeo revolución permanente. De regreso al Odeón pergeño nuevos juegos destinados a lanzar a toda la Ciudadanía Andante en brazos de la Discusión Autónoma (2010: 78-79).

Siguiendo su instinto de artista, ya en el mes de junio y sin ningún conocimiento en creación plástica, Emma decide colaborar en la elaboración de los famosos afiches (carteles). Según nos cuenta en su diario, cualquier ayuda, a estas alturas del conflicto, era bien recibida. Ésta será su última contribución a la Primavera del 68. Ninguna de sus creaciones ha sobrevivido al naufragio.

De su paso por el Atelier Populaire de la Escuela de Bellas Artes de París, tras las huellas de Eduardo Arroyo y Doroteo Arnáiz, Cohen confiesa que no le quedaba otra que

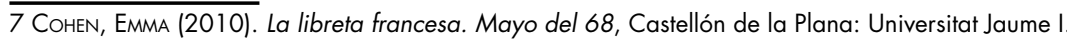

8 «aquí, se juega al juego de las preguntas». Traducción de la autora. 
aprender mientras hacía, tal era su desconocimiento en la materia. Desde limpiar los tamices, echar tinta, pasar la regleta y tender, hasta engalanar con ellos los muros de la ciudad desierta a altas horas de la noche, pasando por proponer proyectos de carteles, muchos rechazados, uno aceptado: «mujer-revolución».

Pero el sueño de la mujer que duerme mientas de sus cabellos ondulados salen las letras de la Revolución, al igual que el suyo, terminan bruscamente y para siempre:

Jueves 27 de junio.- Caí dormida, a punto de completar el tamiz «mujer pensante cuyos pelos se hacen letras»; caí dormida tan en profundo que no desperté cuando entraron. Sólo tras el zarandeo y tras retirarse el haz de luz que me da en los ojos veo máscaras ortópteras y cuerpos trajeados como para incursión abisal, los CRS han entrado en Beaux-Arts, destrozan el Atelier, retiro el rostro, gas, me arrastran hacia fuera, una furgo, no puedo gritar a causa del gas, nadie para defendernos en rue Bonaparte. Beaujon`. Beaujon amanecido, gris, más calmo que al inicio de los sucesos, según los comentarios. [...] Fin del fin (2010: 107-108).

El asalto de los CRS a la Escuela de Bellas Artes, el «fin del fin» del que habla Emma Cohen, acabó con su excepcional aventura parisina, pero, peor aún, representó un paso más hacia la conclusión del movimiento revolucionario. Las elecciones legislativas de los días 23 y 30 de junio, con la victoria de De Gaulle y la derrota de las izquierdas, pondrían el punto final. Pero bastante antes de llegar a este inesperado desenlace, los obreros y las obreras de la gran mayoría de las empresas francesas vivieron una experiencia inolvidable y junto a ellos miles de trabajadores y trabajadoras españoles.

\section{Las obreras españolas en Francia}

Según todos los indicios, la repercusión del Mayo francés en el movimiento obrero español fue bastante limitada, al menos, dentro de nuestro país. Por el contrario, no podemos decir lo mismo de la influencia directa que éste ejerció en los miles de españoles que en ese momento se hallaban trabajando en Francia. Asimismo, la implicación de las obreras españolas, como ahora veremos, no fue nada desdeñable.

Estos hombres y mujeres no dudaron en participar en las manifestaciones y en todos los actos de protesta que se organizaron aquellos agitados días, tampoco titubearon a la hora de secundar la huelga general y de ocupar sus puestos de trabajo. Como los franceses, sintieron que era un momento único en la Historia y que tenían mucho que aportar. La lucha

9 Beaujon es el nombre con el que se conocía al centro policial donde se llevaban a algunos de los manifestantes detenidos y también donde recluían a los extranjeros «incómodos» hasta su expulsión del país. 
iniciada en este país próspero, que les había dado la oportunidad de mejorar sus vidas y las de sus familias, la hicieron suya y la interpretaron como un ejemplo a seguir en su país de origen. No sólo luchaban por mejorar sus condiciones en Francia -peores que las de sus colegas franceses-, querían aprender de la experiencia y trasladar su combate a la España franquista, más sedienta de cambios. En este sentido, la huelga general gala era la versión más parecida a la «huelga general nacional», propuesta por los comunistas españoles para derrocar a la dictadura. Los trabajadores españoles emigrados a Francia aprovecharon el momento excepcional que estaban viviendo para pedir a sus compañeros franceses que les ayudaran a alcanzar este complejo objetivo.

Para conocer el verdadero alcance del compromiso de los trabajadores españoles con esta lucha, el recurso a las revistas comunistas clandestinas, con sus numerosos testimonios de primera mano, es crucial. Así por ejemplo, en la revista Información Española, editada en Bruselas, hemos encontrado un reportaje de la periodista Anita ${ }^{10}$ Dámaso en el que se nos ofrece una serie de datos muy relevantes sobre la implicación de los obreros españoles en la ocupación de la fábrica Renault de Billancourt:

En la fábrica REANULT de Billancourt trabajan dos mil españoles. Dos mil huelguistas apasionados y activos, en su mayoría jóvenes, que participan en los piquetes de huelga -el jueves 15 de mayo la mitad del piquete era español- que se niegan a irse a dormir y viven con entusiasmo extraordinario esa hora histórica.

-Todo esto -me dice un joven- nos enseña mucho, sobre todo a nosotros, los jóvenes, que nunca lo hemos conocido. Y además j̇verdad? nos será muy útil para las luchas de nuestro país... (Información Española, $1^{a}$ quincena de junio de 1968, p. 15).

De entrada, sorprende el gran número de españoles que trabajan en esta empresa: dos mil. De los que se nos dice que son jóvenes en su mayoría y que participan con gran entusiasmo en todas las tareas derivadas de la ocupación, como la constitución de piquetes. Y, como ya hemos comentado, también se advierte el carácter ejemplarizador de esta lucha.

A continuación, dentro del mismo reportaje, la autora pasa revista a otras fábricas en las que hay presencia española. De estos obreros, destaca siempre su predisposición a participar en la huelga y en las ocupaciones, así como su deseo de comunicar estas experiencias a sus colegas de empresa en España y mostrarles su apoyo en la lucha antifranquista. El ambiente que reina en una de las empresas ocupadas -Bendix-, con unos cincuenta empleados españoles, es magníficamente descrito por Dámaso, quien se lleva de regalo un croquis hecho por uno de los ocupantes [Fig. 5]: 


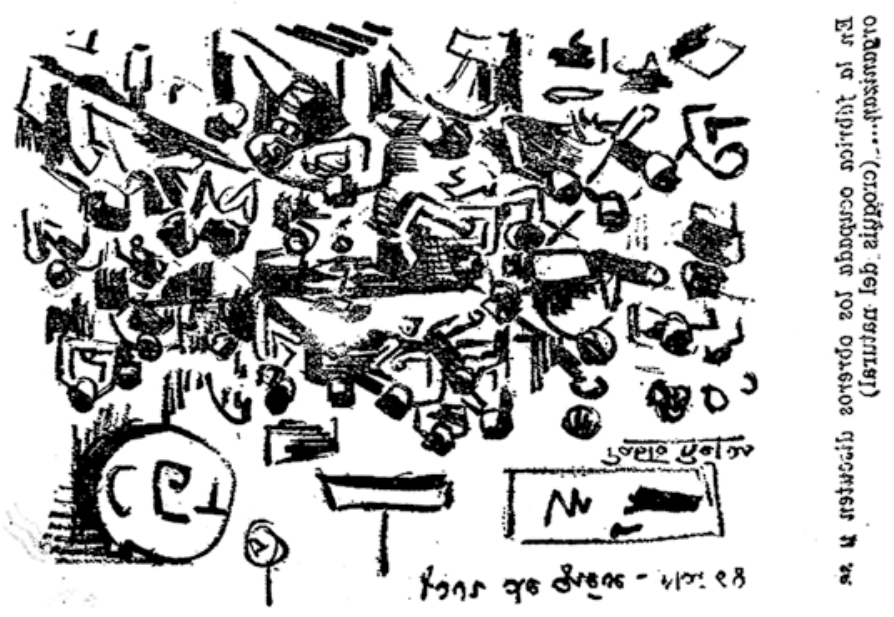

[Fig. 5]. Croquis regalado a Ana Dámaso, en Información Española, $1^{a}$ quincena de junio, p. 15.

Dentro, en la gran sala de la cantina, es un verdadero hervidero. Los obreros organizan la ocupación, discuten, dan muestras de un sentido de responsabilidad y de organización impresionantes. Unos se ocupan de la seguridad. Hay que evitar las posibles provocaciones, filtrar cuidadosamente a los que entran, vigilar los puntos neurálgicos de la fábrica. Otros hablan de la cantina. Es preciso servir comidas a los trabajadores, ocuparse del abastecimiento. Algunos van a gestionar con la municipalidad obrera el que les sea asegurada la comida a los niños de los huelguistas. Varios distribuyen prensa sindical. Todos, en grandes y pequeños grupos, discuten mil problemas, con pasión a veces, pero siempre fraternalmente, siempre llegando a encontrar la solución justa. Preparan un mitin para esta tarde. Hay artistas -me dicen- que van a venir voluntarios a prestar su concurso. El ambiente es extraordinario de tranquila seguridad, de dignidad obrera... (Información Española, $1^{a}$ quincena de junio de 1968, p. 15).

En el siguiente número de Información Española, el de la $2^{a}$ quincena de junio, esta misma periodista nos relata un episodio protagonizado por trabajadoras españolas:

En Mecano, en La Courneuve, trabajan muchas mujeres españolas. Jamás había podido constituirse allí el sindicato obrero. Tenían miedo. Cuando el odiado director se acercaba, las españolas decían atemorizadas: "Cuidado, ahí viene el "Mobyleta"...». La huelga ha barrido todo eso. Las españolas, entusiasmadas, incansables, participan en masa en los piquetes de 
huelga; se ha constituido el sindicato, se sienten fuertes.

-La gente -nos dicen con emoción- se porta bien. Nos traen patatas, comida, ayuda, es fantástico. Y se acabó el «Mobyleta». Ahora le gritamos «iFuera Mobyleta» en sus narices y se tiene que aguantar... No soltaremos la fábrica hasta que cedan. ¡Cuánto estamos aprendiendo en estos días! (Información Española, $2^{a}$ quincena de junio de 1968, p. 15).

La edición de la primera quincena de julio, en la sección «La mujer tiene la palabra», presenta el testimonio de una obrera española, oculta bajo las iniciales $G$. R., que relata un interesante capítulo de la lucha de sus compañeras en una fábrica francesa ocupada:

los obligamos a que entregaran el boleto para cobrar el subsidio familiar. Por cierto que para extender el boleto entraron -con permiso del comité de huelga- un alto jefe y dos ayudantes. Hicieron algunos y luego se negaron a seguir: «Estamos en huelga», dijeron con todo el cinismo. Informado el personal de lo que ocurría, numerosas mujeres se abalanzaron al despacho. "O nos hace el boleto o no sale de la fábrica», le decían al jefe; y una le tenía cogido por la corbata. ¡Ya lo creo que hizo los boletos! (Información Española, $1^{a}$ quincena de julio de 1968, p. 7).

En la siguiente edición, la de la segunda quincena de julio, y en esta misma sección, encontramos los testimonios de varias mujeres españolas que han participado, como miembros de pleno derecho, en el movimiento huelguístico francés. Curiosamente, esta información ya fue publicada en Alborada, un «periódico femenino español editado en París». En el artículo, titulado «Experiencias de 3 españolas en una gran huelga», se recogen las voces de Magdalena, Luisa, Carmen, Mari-Carmen y Elvira. Las tres primeras describen su participación activa en la promoción de la huelga en sus respectivas empresas. Todas ellas se presentan como las promotoras de dicha iniciativa, con un resultado muy positivo, pues la mayoría de sus demandas son aceptadas, y todas acaban afiliándose a la CGT y creando una sección en sus fábricas. Las dos últimas, Mari-Carmen y Elvira, delegadas españolas en un congreso de la UFF en Nimes, reflexionan sobre el nuevo papel de la mujer en la sociedad española.

El hecho de participar en un congreso de esta índole -«para reforzar la participación de la mujer en la lucha por la paz»- ya es un gesto de gran trascendencia en sí mismo; una muestra del interés de algunas españolas, cada vez más numerosas, por subirse al carro de la lucha por la mejora de las condiciones de vida de éstas a nivel europeo. El artista Doroteo Arnáiz nos comentó que tuvo la suerte de asistir a una de estas primeras reuniones feministas en las que los problemas de las mujeres comenzaban a ponerse sobre el tapete del debate social.

Pero volviendo al artículo que nos ocupa, recordaremos las ideas más importantes 
transmitidas por estas dos militantes. Según ellas, en España, se estaba asistiendo a un cambio de paradigma, es decir, se estaba viviendo toda una revolución con el nacimiento de un nuevo tipo de mujer, de la mano, precisamente, de las jóvenes generaciones. Esta nueva mujer se negaba a encasillarse en el papel de buena hija, buena esposa y buena madre que la ideología franquista venía imponiéndole desde hacía muchos años. Incluso las mujeres que poseían una carrera universitaria se veían obligadas a abandonar sus trabajos después de casarse. Esto, reconocían, estaba empezando a cambiar. Los frutos de su esfuerzo académico se preveían, a partir de entonces, para toda su vida activa. Por otro lado, las nuevas necesidades económicas del país apuntaban a un cambio en esta dirección. Otro de los puntos abordados en la entrevista a estas dos mujeres era el de la lucha de sus compañeras en el marco de un movimiento más vasto: el combate por la democracia; movimiento en el que las mujeres tenían un gran peso. De las acciones en pro de esta lucha, tanto a nivel general como de barrio, ponían varios ejemplos:

- En Getafe, entre los obreros detenidos habían [sic] algunos menores de edad, fueron maltratados por la policía. Inmediatamente las mujeres hicieron un documento de protesta contra los malos tratos y las detenciones de Zarzalejo, bajo el cual recogieron 295 firmas. Una delegación lo entregó al Ministerio de Justicia el día 18 de Abril [sic]. Después se llevó a los periódicos una fotocopia del documento con las firmas y el matasellos de la entrega al ministerio.

- ¿Algún ejemplo de la actividad en los barrios?

- Sí. San Fernando está completamente desatendido. Por la noche no hay médico ni ambulatorio. Una noche, un niño enfermo murió por falta de atención médica, por no haber podido ser trasladado a tiempo. Las mujeres democráticas hicieron un documento y recogieron más de mil firmas. Fueron a los médicos que están de día, y todos firmaron. A las escuelas, a los curas de la parroquia, que también firmaron y pusieron el sello parroquial. Lo mismo hicieron las monjas del colegio (Información Española, $2^{a}$ quincena de julio de 1968, p. 9).

El artículo concluye dando información sobre la composición de este movimiento democrático de mujeres -marxistas y católicas- y sobre su prestigio y las nuevas adhesiones. Se estaban dando unos pasos muy importantes en dos ámbitos clave de la sociedad española del momento, a saber, en la lucha por mejorar la situación de las mujeres y en el combate sin tregua contra una dictadura que ya llevaba demasiado tiempo lastrando el progreso de todo un país.

El 68 en España no se puede deslindar de estas batallas animadas por hombres y mujeres dispuestos a dejarse la piel para que la realidad fuera otra muy diferente. Los sucesos de Francia de ese año fueron sin duda un ideal regulativo y una incuestionable fuente de inspiración para todos ellos. He aquí nuestro modesto homenaje. 


\section{Bibliografía}

Badenes Salazar, Patricia (2006). La estética en las barricadas. Mayo del 68 y la creación artística, Castellón de la Plana: Universitat Jaume I.

_ (2018). Fronteras de papel. El Mayo francés en la España del 68, Madrid: Cátedra.

BARBEY, Bruno et al. (1998). Mai 68 ou l'imagination au pouvoir: Trente-huit photographies de Bruno Barbey, deux cent soixante-dix-huit affiches, París: La Différence.

CARR, Raymond et al. (2007). 1939/1975 La época de Franco, Madrid: Espasa Calpe.

Carrero Blanco, Luis (1974). Discursos y escritos 1943/1973, Madrid: Instituto de Estudios Políticos.

Carrillo Solares, Santiago (2006). Memorias, Barcelona: Planeta.

Cohen, Emma (2010). La libreta francesa. Mayo del 68, Castellón de la Plana: Universitat Jaume.

Chollet, Laurent (2007). Mai 1968. La révolte en images, París: Hors Collection.

DíAz, Ángel (2010). «El Colegio de España en París, residencia de artistas e investigadores y protagonista desconocido del 68» en El Mundo, miércoles 10 de febrero de 2010.

Fraga Iribarne, Manuel (1980). Memoria breve de una vida pública, Barcelona: Planeta.

Franco Salgado-Araujo, Francisco (1976). Mis conversaciones privadas con Franco, Barcelona: Planeta.

Fusl, Juan Pablo, VILAR, Sergio y Paul Preston (1983). De la dictadura a la democracia. Desarrollismo, crisis y transición (1959-1977) en Historia de España, n 13, Historia 16, Año VIII, Extra XXv, febrero 1983.

Glucksmann, André y Raphaël Glucksmann (2008). Mai 68 expliqué à Nicolas Sarkozy, París: Denoël.

Gracia, Jordi y Miguel Ángel Ruiz Carnicer (2004). La España de Franco (1939-1975). Cultura y vida cotidiana, $\mathrm{n}^{\circ} 34$, Madrid: Síntesis.

Jáuregul, Fernando y Pedro Vega (2007). Crónica del Antifranquismo, Barcelona: Planeta.

JoffRIN, Laurent (1988). Mai 68: Histoire des Événements, París: Seuil.

KURLANSKY, Mark (2004). 1968. El año que conmocionó al mundo, Barcelona: Destino.

LINHART, Danièle (Prefacio) (1989). Mai 68, par eux-mêmes. Le mouvement de Floréal, an 176, París: Éditions du Monde Libertaire.

Moradiellos, Enrique (2003). La España de Franco (1939-1975). Política y sociedad, n³3, Madrid: Síntesis.

PAstor, Jaime, Romero, Miguel y Manuel GARí (eds.) (2008). 1968. El mundo pudo cambiar de base, Madrid: Los Libros de la Catarata-Viento Sur. 
PICQ, Françoise (1993). Libération des femmes. Les années-mouvement, París : Seuil.

Ross, Kristin (2002). Mai 68 et ses vies ultérieures, París: Éditions Complexe.

Rotman, Patrick (2008). Mai 68 raconté à ceux qui ne l'ont pas vécu, París: Seuil.

SORIANo LORENTE, Juan Carlos (2008). Pilar Narvión. Andanzas de una periodista perezosa, Tervel: Tirwal.

Sort Creus, Albert (2016). «L'amor situacionista: els límits de la subversió dels afectes en la crítica de la vida quotidiana», Trabajo de Fin de Grado de Humanidades (Jordi lbáñez, director), Barcelona: UPF.

VANEIGEM, Raoul (1992). Traité de savoir-vivre à l'usage des jeunes générations, París: Folio Actuel.

VIÉNET, René et al. (1998). Enragés et situationnistes dans le mouvement des occupations, París: Éditions Gallimard.

YsÀs, Pere (2004). Disidencia y subversión. La lucha del régimen franquista por su supervivencia, 1960-1975, Barcelona: Crítica.

Zancarini-Fournel, Michelle (2008). Le moment 68. Une histoire contestée, París: Seuil.

\section{Hemerografía (por orden de aparición)}

Nuestra Bandera, tercer trimestre de 1968, p. 65.

Pueblo, 7 de mayo de 1968, p. 13; 9 de mayo de 1968, p. 12 y 13 de mayo de 1968, p. 8. Destino, 1 de junio de 1968, p. 29.

Arriba, 24 de mayo de 1968, p. 12.

El Alcázar, 22 de mayo de 1968, p. 3.

Información Española, $1^{a}$ quincena de junio de 1968, p. 15; $2^{a}$ quincena de junio de 1968, p. $15 ; 1^{a}$ quincena de julio de 1968, p. 7 y $2^{a}$ quincena de julio de 1968, p. 9. 